\title{
Enhancing Business Sustainability and Competitive Advantage by Using a Strategic Mathematical Computing Model
}

\author{
Yi-Cheng Yeh $\mathbb{D},{ }^{1}$ Yu-Hsi Yuan $\mathbb{D},^{2}$ and Chia-Huei Wu $\mathbb{D}^{3}$ \\ ${ }^{1}$ Department of International Economics and Trade, Jiangsu University of Technology, No. 1801, Zhongwu Road, \\ Changzhou 213001, Jiangsu, China \\ ${ }^{2}$ Department of Labor and Human Resources, Chinese Culture University, No. 55, Hwa-Kang Road, Yang-Ming-Shan, \\ Taipei 11114, Taiwan \\ ${ }^{3}$ Department of Hotel Management and Culinary Creativity, Minghsin University of Science and Technology, \\ No. 1, Xinxing Road, Xinfeng, Hsinchu 30401, Taiwan \\ Correspondence should be addressed to Yu-Hsi Yuan; yuc88g@gmail.com
}

Received 8 February 2021; Revised 10 June 2021; Accepted 30 June 2021; Published 10 July 2021

Academic Editor: Kai Zhang

Copyright $(92021$ Yi-Cheng Yeh et al. This is an open access article distributed under the Creative Commons Attribution License, which permits unrestricted use, distribution, and reproduction in any medium, provided the original work is properly cited.

Nowadays, enterprises are trying hard to reach sustainability when the industry faces the challenge of high cost in the era of meager profit. Companies with corporate sustainable approaches based on cost leadership are trying to reduce operational expenses, increase business efficiency, and implement comprehensive cost reductions within their organisations. Cost is a strategic issue for businesses to survive and stand out. The deployment of profit costs is becoming strategically important to be sustainable and competitive in the market. The research design of this study integrates both qualitative and quantitative methods. 143 valid responses to snowball sampling in Taiwan (108 responses) and mainland China (35 responses) and 24 interviews with executivelevel employees in Taiwan were conducted. In addition, a total of 51 companies' financial statements were reviewed to triangulate the foundation of research findings. Reducing costs strategically should be considered as a principal concern of a firm that wants to make its efforts for business sustainability. The result shows that nonstrategic costs are between 10 and 30 percent of the sales turnover (revenue) in a firm, and strategic costs normally account for 70 to 90 percent of its all costs. Furthermore, only $20 \%$ really makes a difference to stand out from other market players. This provides a new orientation of cost management opinion that there is a need for paying more attention and extending the concept of strategic cost management to the management of nonstrategic costs. It is also supported that the dichotomy of nonstrategic and strategic is a viable and practical way for managing all costs across sectors, industries, and business scales from a strategic and sustainable perspective.

\section{Introduction}

Cost reduction is used by firms to increase profits and can be interchanged with "profit enhancement." However, it is incredible, that often well-thought cost management is overlooked even though the organisation is doing its best in everything to improve profit $[1,2]$. It is argued in the study that cost management should occupy a vital position in enhancing business profitability and corporate sustainability. With the rise of the lean company [3] and ongoing market competition, firms should act proactively to manage costs strategically. Financial reporting and clerkship are no longer the focus of cost management. The rising emphasis is on strategic management to assist organisational development and achieve its strategic goals for business sustainability. Cost management has now moved to a strategic orientation-strategic cost management [4-13].

It is vital to control the costs incurred in the business and to find innovative ways to stay active and succeed in a competitive scenario. By measuring the reasons for conducting cost reduction and examining their differences in the context of different sectors and industries as well as respondents whether personally involved in managing costs, the study provides a way to divide costs into nonstrategic and strategic and fine-tunes their definitions made by field practitioners such as Fifer [14] and Machin [15]. 
The redefined term of nonstrategic cost is costs required to operate the business but do not deliver sales, profit, quality, and product value directly $[16,17]$. Is holding the belief of cost leadership to profit optimisation by minimising nonstrategic costs a true strategic shift for sustainability or just a roadmap created for business collapse as Shufelt [18] stated? Is the supposition that nonstrategic costs are 10 to 30 percent of a firm's sales and strategic costs of approximately 70 to 90 percent $[14,16,19,20]$ in line with reality? What are the related concepts and key literature of managing nonstrategic costs? All these questions trigger the researchers' intention to seek the answers and explore the meaningfulness of managing nonstrategic costs.

The research adopts a postpositive position to survey and interview business stakeholders, located in Taiwan and mainland China (two sides of Taiwan Strait). From this, the study exposes issues related to the management of nonstrategic costs. It is debated in this study that organisations can enhance their competitive advantages by paying more attention to those costs not strategic, in particular during the COVID-19 pandemic. Besides, the significance of the research is to scholastically examine the dichotomy of costs and explore the strategic position of nonstrategic costs in a competitive market, recognise the value and hidden income delivered by administrative personnel, and fulfill the missing piece in the research literature of managing costs from a strategic and sustainable perspective.

\section{Literature Review}

2.1. Sustainable Business Strategy. How should business sustainability fit in core strategy? Two common types of competitive approaches are based upon cost leadership and differentiation [21]. Nevertheless, to the firm and the responsible person in charge of P\&L (profit and loss), the quickest means to produce additional profit is cost reduction. It is just more self-controllable to cut costs than it is to get more businesses. Clearly, it is even more difficult to ask for business from other persons than saving your own money as the study's authors debated. Atkinson et al. [22] believed that costs are manageable and can be minimised by employing lean approaches to remove unnecessary costs out of a firm and achieve more with less.

On the basis of overall cost leadership and lean philosophy, a cost-effective firm makes all efforts to optimise costs [21]. Ironically, simply asking employees to leave the company without considering ethical labor practice of corporate social responsible firms $[23,24]$ has often been in the news media. There is no comprehensive strategic consideration and oganisation structure in place for managing costs effectively and efficiently but only budgeting [16]. As Grundy [25] pointed out, in the organization, the situation that cost management is "the land that strategy almost forgets" needs to be corrected for maximising total profits, not just total revenue.

While cost management grew into urgent importance to an organisational continuity, Cooper [26] recognised two evolving tendencies. First, new practices of managing costs are needed, and, second, more participants in the organisation are heavily associated with managing costs. The augmented significance of managing costs has expedited cost management into a more strategic purpose. Cost is a strategic issue [25]. Individuals in the organisation should become active in the strategic implementation of the cost reduction process.

2.2. Strategic Cost Management. A rising concept of cost reduction with heavy involvement from participants in the organisation, strategic cost management (SCM) initially promoted by Simmonds during the 1980s, is the process of managing costs strategically and can be adopted in manufacturing and service as well as nonbusiness entities to enhance their strategic positions [27-29].

Since the 1980s, strategic cost management has been realised differently in various ways in the related literature. Shank and Govindarajan [30] indicated that strategic cost management uses the traditional body of knowledge called cost analysis to the knowledge developing of strategy formulation and implementation. Cooper and Slagmulder [6] and Welfle and Keltyka [31] debated that strategic cost management is to apply the instruments and techniques of managing costs while reducing costs and accordingly strengthen the firm's strategic position.

Horváth and Brokemper [32], however, commented that strategic cost management is the practice of talking into the structure, behavior, and level of costs to capture and secure strategic advantages in a competitive way [33]. Cost containment to strategic cost management is a principle directing every value conduct, business, and individual behaviors. The literature search has elucidated that strategic cost management has an extensive emphasis. It is not limited to the cost reduction itself and it has even more care over the application of cost information for making strategic decisions.

2.3. Strategic Reduction of Nonstrategic Costs. On incorporating the law of simplicity and principles of strategic cost management $[16,34]$, costs can be categorised into nonstrategic and strategic types to focus on the interrelationship among profit, revenue, cost, and value [16]. However, there were no scholastic researches that emphasised nonstrategic costs by taking a strategic viewpoint, but by just only mentioning the idea of nonstrategic costs [18, 35-38]. Until recently, only a few attempts have so far been made to really address nonstrategic costs and overhead resources from a strategic angle $[16,38]$. The necessity to investigate the importance of nonstrategic costs is critical.

On this condition, firms can further take the idea of Lean to minimise nonstrategic costs and strengthen business sustainability without weakening competitive advantage. Ignoring the management of nonstrategic costs will cause either excessive money spent on nonstrategic items or limited contribution to a company's sales, product value, and quality, or profit. Managing nonstrategic costs is a strategic issue for a firm to be sustainable and competitive in the market. 
To accomplish the purposes of the research, the following description reveals the linkage between the researchers' literature review and the empirical study.

\subsection{Links between Key Research Questions and Literature.} The existing literature supported that most organisations have no centralised cost control unit, committee, or department $[16,39]$. Organisations often do not treat profit building through reducing costs as an organisational function but do have functional units such as sales and marketing and research and development [39]. No dedicated control unit or individual accountable for managing costs becomes usual in the firms [16]. Cost management is the area that strategy nearly disremembered [25]. Less attention on cost management is paid by companies. Managing costs effectively and efficiently from a strategic perspective, therefore, is vital.

However, there is no significant difference on the importance scales and causes of doing cost management between private and public sectors in the reasons including revenue generation, profit contribution, organisational reputation, people management, and quality assurance [16]. Between sectors, the private and public attach more importance to revenue generation and company reputation, respectively [16]. Thus, the following research questions have further emerged:

(1) Is there a significant difference on the reasons of managing costs between manufacturing and service industries?

(2) Will the answers be different between the participants with personal involvement and participants without personal involvement for conducting cost savings?

Classifying costs into two types, nonstrategic and strategic, offers an innovative approach to review costs from a strategic perspective. However, if focusing on controlling nonstrategic costs creates a roadmap for failure as Shufelt [18] stated or controversy, provide a possible source of the comparative edge [16]. The different viewpoints bring out the following research question.

(3) Is reducing nonstrategic costs a path to failure? Can managing nonstrategic costs be a strategic advantage to business profit and sustainability?

Moreover, the positive relationship existing between the tracing levels and the cost percentages in the manufacturing industry [40] is sustainable across industries [16]. Nonstrategic cost is the minor portion but less risky and easier to receive higher saving than that from strategic costs [16]. The raised questions are as follows:

(4) Is the assumption that nonstrategic costs accounting for 10 to 30 percent of a company's revenue in line with reality? Is it meaningful to cut nonstrategic costs, the minor portion?

The previously mentioned research questions produced from the review of the existing literature have triggered the interest of authors to come out with answers and solutions through an academic route.

In comparison with the existing literature, the proposed study differs from the previous works in the following aspects. First, this work focuses on the dichotomy of strategic and nonstrategic costs considering revenue, profit, quality, and value as determinants to create a strategic mathematical computing model. Second, earlier studies mainly dealt with operational improvement and sources of profitability. The present paper promotes strategic cost management but explores the strategic importance of nonstrategic costs. Third, unlike the earlier papers, the paper examines how nonstrategic costs are related to business sustainability and competitive advantage. Fourth, as indicated earlier, the proposed model uses a mathematical approach to view costs from a strategic perspective and presents the profit-leverage effect of saving nonstrategic costs.

The research data and methodology for exploring the argument that a strategic shift to nonstrategic costs might need to be performed for being competitive and sustainable is discussed in the following sections.

\section{Research Design}

3.1. Methodology. Postpositivism [41] employs multiple methods to triangulate the actuality $[42,43]$. Besides a review of existing literature, the combination of statistical findings with 143 valid responses from a structured questionnaire through snowball sampling further supported by interviews with 24 participants could provide a triangulated validation [44] to extract a more precise representation of the research issues related to costs nonstrategic. It is the study authors' intention to examine the results in multiple ways and broadly explore the perspective and views of others via a postpositive perspective.

3.2. Quantitative Data Collection. A snowball technique [45] was used to obtain a large sample, by which willing respondents invited their associates on business or private occasions to participate in the survey. Most participants work in firms underlining profit and cost management as well as strategic goals. Using the known contacts, the researchers have related personal or business connections for accessibility to collect data as an efficient and proper approach [46-48].

As shown in Table 1, about $62.9 \%$ of participants were from the service industry and the rest of them (37.1\%) were from the manufacturing. The samples primarily from the service industry were consistent with the research's intention to examine if the findings of literature in the manufacturing industry could be confirmed in the service industry also.

Table 2 displays the age and education groups of participants. Approximately $37.8 \%$ of respondents were below 40 years old. $97.2 \%$ of them had college or above education. Apart from $33.6 \%$ of participants with clerical duties, the larger part of them (66.4\%) had management jobs like supervisor, managing director (MD), and chief executive officer (CEO). The respondents turning into older, more 
TABle 1: Demographics of survey participants by industry.

\begin{tabular}{lccc}
\hline & Type & Frequency & Percentage \\
\hline \multirow{2}{*}{ Industry } & Service & 90 & 62.9 \\
Total & Manufacturing & 53 & 37.1 \\
\hline
\end{tabular}

Source: authors.

TABle 2: Demographics of survey participants, including age, education, and position.

\begin{tabular}{|c|c|c|c|}
\hline Demographics & Group & Frequency & Percentage \\
\hline \multirow{5}{*}{ Age } & $<29$ & 39 & 27.3 \\
\hline & $30-39$ & 15 & 10.5 \\
\hline & $40-49$ & 44 & 30.8 \\
\hline & $50-59$ & 33 & 23.1 \\
\hline & $>60$ & 12 & 8.4 \\
\hline Total & & 143 & 100.0 \\
\hline \multirow{3}{*}{ Education } & High school & 4 & 2.8 \\
\hline & College & 88 & 61.5 \\
\hline & Graduate & 51 & 35.7 \\
\hline Total & & 143 & 100.0 \\
\hline \multirow{7}{*}{ Position } & Board chairperson & 15 & 10.5 \\
\hline & $\begin{array}{c}\mathrm{MD} / \mathrm{CEO} / \text { president } / \\
\mathrm{GM}\end{array}$ & 17 & 11.9 \\
\hline & Financial supervisor & 21 & 14.7 \\
\hline & $\begin{array}{l}\text { Administration } \\
\text { supervisor }\end{array}$ & 15 & 10.5 \\
\hline & Supervisor/others & 27 & 18.9 \\
\hline & Clerical/general admin & 9 & 6.3 \\
\hline & Clerical/others & 39 & 27.3 \\
\hline Total & & 143 & 100.0 \\
\hline
\end{tabular}

Source: authors.

educated, and senior exactly echo the profile of decisionmaking levels in most organisations. It is established that the participants had the intelligence needed to fully answer the questions because (1) they were engaged in the firm's profit and loss to some degree and were aware of organisational management; (2) they had the knowledge needed to provide answers for data analysis; (3) the participants from various job functions and levels could provide diverse opinions and had a fundamental comprehension on costs; (4) they should presumably take more care of performance measures, which is essential to correctly examine the helpfulness of cost reduction in practice; (5) the participants not having answers for some particular questions were in a position to seek help from someone who could.

Based on Table 3, 57.3\% of the samples were from medium- and large-sized firms with annual sales larger than $£ 3,816,794$ (50 million US dollars at $£ 1=$ USD 1.31), and around $24.5 \%$ of the sampled organisations were publicly owned. These sample characteristics had the data collection easier as their general information such as financial data is somewhat reachable openly. Moreover, the samples including a considerable number of small-sized companies were along the lines of the research plan to represent the population as $42.7 \%$ of sampled firms had yearly turnover of less than $£ 3,817,000$ (USD 50 million US dollars), and 30.1\% of them had the number of employees less than 50 . The demographics mirror that $97.7 \%$ of Taiwanese companies $[49,50]$ and $97.8 \%$ of mainland Chinese companies [51] are SMEs (small and medium-sized enterprises) as defined by the government authorities. The difference of the study's sample from the authority's distributions also reveals a more noteworthy profit generation of managing nonstrategic costs and more accessible and transparent information of larger companies.

Furthermore, only $24.5 \%$ of the respondents defined their firms as low performers in comparison with other market players (see Table 4). A large number of participants reported that their firms were average sales performers at least, so the causes for conducting cost savings were not principally thanks to their low sales. The response was sustained afterwards by higher percentages of low continuous competitiveness and profit margins than that of poor sales performance.

3.3. Qualitative Data Collection. In addition to exploring the significance of costs not strategic, the study is intended to find a direct connection between the bottom line profit and nonstrategic costs, which is not a customary emphasis by firms; nonstrategic costs are not vital at initial thought as strategic costs and revenue are the first priorities. As mentioned, the employment of quantitative and qualitative approaches besides the literature review can triangulate the findings to establish the basis of releasing the hidden profit by reducing nonstrategic costs.

As for personal interviews (see Table 5), the 24 participants aged between 30 and 60 years old were from the authors' current personal and business networks mainly. Amid them, 79\% were managers or beyond, so they well understood the organisational situations and could confirm the survey results to some extent. Taking the aforesaid issues into consideration, it is reasoned that the methods applied and data or information collected in the research statistically ensure content validity. Beyond 98\% of responses showed that the methods covering survey and interview were well structured with good content.

\section{Findings}

4.1. No Accountability Unit for Cost Optimisation. Most organisations do not have a standing unit for cost management but have sales, marketing, and other departments included in their organisation structure $[16,39]$. As the majority of firms do not see profit creation by reducing costs as an organisational function [39], little attention to managing costs could be given by companies. The auditing director of a well-known international bank stated the following.

"Costs are not well managed in the bank.....there is no structured platform to fully manage all cost items but just keeping costs within the budget.......No one does the collaboration jobs....Same office supplies are purchased over and over, even though there is stock in the storage." 
TABLE 3: Demographics of survey participants, including annual revenue, company size, and business type.

\begin{tabular}{|c|c|c|c|}
\hline Demographics & Groups & Frequency & Percentage \\
\hline \multirow{4}{*}{ Annual revenue } & $<£ 3,816,794$ (USD50,000,000; 50M) & 61 & 42.7 \\
\hline & $£ £ 3,816,794-£ 7.633 .588$ (USD100M) & 28 & 19.6 \\
\hline & $£ 7.633 .588-£ 190,839,695$ (USD250M) & 16 & 11.2 \\
\hline & $>£ 190,839,695$ (USD250M) & 38 & 26.6 \\
\hline \multirow[t]{3}{*}{ Total } & & 143 & 100.0 \\
\hline & $<9$ & 12 & 8.4 \\
\hline & $10-49$ & 31 & 21.7 \\
\hline \multirow[t]{3}{*}{ Number of employees } & $50-99$ & 27 & 18.9 \\
\hline & $100-499$ & 36 & 25.2 \\
\hline & $>500$ & 37 & 25.9 \\
\hline \multirow[t]{4}{*}{ Total } & & 143 & 100.0 \\
\hline & State owned & 27 & 18.9 \\
\hline & Nongovernmental org. & 12 & 8.4 \\
\hline & Sole proprietorship & 13 & 9.1 \\
\hline \multirow[t]{4}{*}{ Business ownership } & Partnership & 4 & 2.8 \\
\hline & Private company & 52 & 36.4 \\
\hline & Pubic company & 26 & 18.2 \\
\hline & Public international company & 9 & 6.3 \\
\hline Total & & 143 & 100.0 \\
\hline
\end{tabular}

Source: authors.

TABle 4: Demographics of survey participants by business performance.

\begin{tabular}{lccc}
\hline Groups & Frequency & Percentage & $\begin{array}{c}\text { Cumulative } \\
\text { percentage }\end{array}$ \\
\hline Low performer & 35 & 24.5 & 24.5 \\
Average & 75 & 52.4 & 76.9 \\
performer & 33 & 23.1 & 100.0 \\
High performer & 143 & 100.0 & \\
Total & &
\end{tabular}

Source: authors.

TABLe 5: Demographics of interview participants.

\begin{tabular}{lccc}
\hline Demographics & Groups & Frequency & Percentage \\
\hline \multirow{2}{*}{ Age } & $<40$ & 2 & 8.3 \\
Total & $>40$ & 22 & 91.7 \\
& & 24 & 100.0 \\
Education & College & 14 & \\
& Graduate & 10 & 48.3 \\
Total & & 24 & 100.0 \\
\hline \multirow{2}{*}{ Industry } & Service & 13 & 54.2 \\
Total & Manufacturing & 11 & 45.8 \\
\hline \multirow{2}{*}{ Position } & & 24 & 100.0 \\
Total & Clerk & 5 & 20.8 \\
\hline
\end{tabular}

Source: authors.

A group administration head from Chinese restaurant chain concurred with the comments given by the auditing director.

"The chief executive officer promoted from sales side last year is a sales-oriented leader. As far as the group delivers good sales, he does not care much about costs......The restaurant group has a regular meeting every Monday to thoroughly review revenue but not for cost monitoring."

The situations leaving no one accountable for managing costs become usual in organisation. A finance manager from a bakery chain stated the following.

"One of the jobs I have is budgeting but surely not to control costs. I clearly do not have work force as well as capacity for conducting that and see no individual or unit in the group for that also."

These statements from the previously mentioned participants obviously back that no central control department was accountable for managing costs, and little attention and few resources were paid to cost control. Nevertheless, some enhancements can be delivered as soon as a centralised function with overall accountability under the highestranking executive of a firm is structured. A senior vice president heavily participating in reducing overall costs from the banking industry testified as follows.

"The cost reduction program was never successful under [the former chief executive officer] command but now costs seem well controlled under a centralised unit with the current CEO's strong support....the cross functional committee teamed by special assistant to CEO has the total ownership of cost management now. I clearly see the significant difference and enhancement. People now care about cost management as the CEO does care."

4.2. No Significant Reason Difference across Industries for Conducting Cost Savings. There is no significant difference between private and public sectors on conducting cost 
reduction; however, the private sector attaches more significance to sales creation than the public sector [16]. A senior executive from the private sector agreed that sales creation should be cared more earnestly than those institutions from the public sector.

"Sales revenue and net margin are two main concerns we have more than not-for-profit organisation funded by the government. As you might know we as a profit organisation pay value added tax (VAT) based on sales and income tax based on earnings, we certainly must make our best efforts on revenue, the mainstream sentiment of our business now."

Considering the industry factor, the research additionally investigated if respondents from different industries may have varying answers (see Figure 1).

If the computation under a $95 \%$ confidence interval (CI) is applied repeatedly, $95 \%$ of the time the interval will cover the actual mean. Figure 1 shows the states for manufacturing and service industries. The error bars display the ranking places for profit contribution $\left(M_{\text {Service }}=4.38 ; M_{\text {Manufacuring }}=4.81\right)$, revenue generation $\left(M_{\text {Service }}=3.43 ; M_{\text {Manufacuring }}=3.77\right)$, company or organisation reputation $\left(M_{\text {Service }}=2.29 ; \quad M_{\text {Manufacuring }}=1.63\right)$, quality assurance $\left(M_{\text {Service }}=3.09 ; M_{\text {Manufacuring }}=2.92\right)$, and people management $\left(M_{\text {Service }}=1.81 ; M_{\text {Manufacuring }}=1.87\right)$ measured under $95 \%$ confidence intervals for the reason differences by the survey participants from both industries. There is no substantial difference between the manufacturing and service industries in each situation due to the coefficient did not cross zero. Furthermore, it reflected that a $p$ value smaller than 0.05 did not touch the significant grade $[52,53]$.

In Table 6, the means of causes for managing costs are presented and the means' differences are measured for statistical significance.

Although quality level at a manufacturer directly influencing demand of the product is a major challenging task $[54,55]$, the service industry gives significantly more importance to quality assurance as a reason for managing costs than the manufacturing industry. At the 5\% level between manufacturing and service industries, the manufacturing industry however attaches significantly more importance to managing costs by reason of profit contribution. "I have personally felt so unpleasant with the small profit margin in our Taiwan operation" was the remark from a deputy manager of a manufacturer who highlighted the importance of profit enhancement by reducing costs for manufacturing companies. Yet, a human resource director from a consulting firm pointed out the following.

"Cost management is important and should be well handled across industries. I see no difference for the ranks in order of importance for conducting cost reduction either in service or manufacturing industry although a service company like us may attach more significance to quality assurance than a manufacturer."

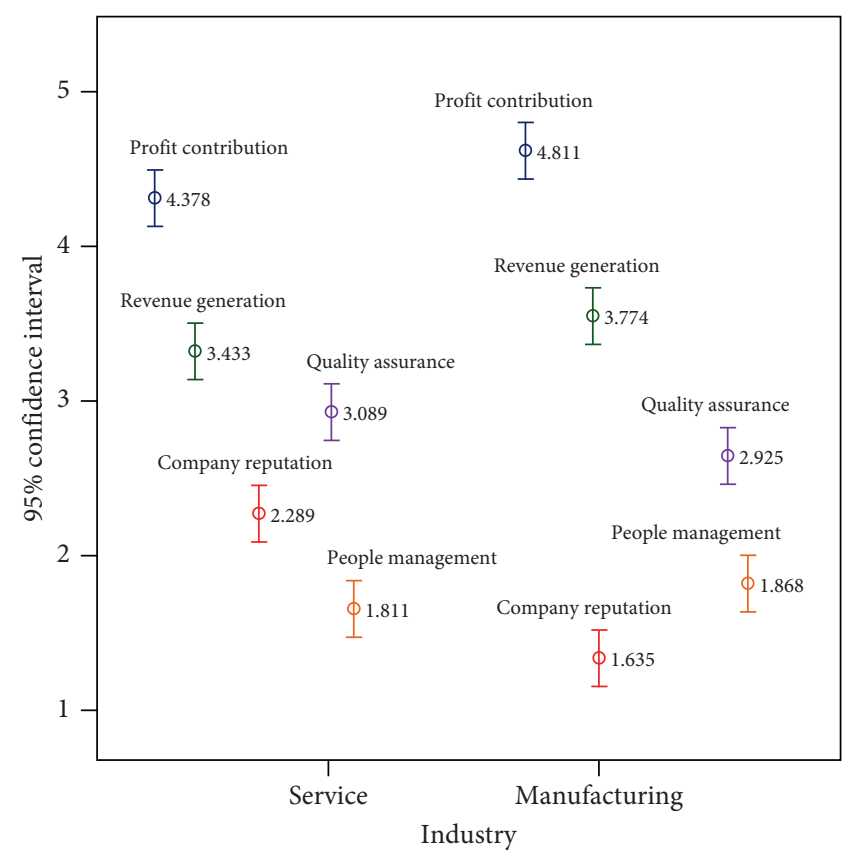

FIgUre 1: Comparison by industry under confidence interval of 95\%. Source: authors.

4.3. No Major Difference for Participants with/without Involvement in Cost Savings. Selling more or saving more are two common ways to increase a firm's profit. The questionnaire outcomes supported that those considerations clearly linked to revenue generation, profit contribution, and quality assurance are more significant to participants for managing costs and further confirmed the definition of strategic costs as those costs directly bringing in revenue, profit, of product value $[16,56]$. In summary, the results offer evidence that efficiency enhancement and cost reduction without discounting the organisational effectiveness as promoted by Peter Drucker [57], which protects business profit, play an essential role in organisation-wide strategies.

However, two sample groups, participants with personal involvement and participants without personal involvement in cost-saving projects, are examined to investigate if their means are distinct significantly. An independent-samples t-test is adopted to detect if the means from these two samples are unlike. The words from a senior manager not personally involved and a supervisor personally involved in managing costs support that no difference in the order of significance for the five main causes (revenue generation, profit contribution, quality assurance, people management, and organisational reputation).

"It is practical to firstly think about sales creation, profit generation, and quality control before personnel management and corporate fame. This is the right way to make money and meet stakeholders' expectation, which is sensible to me although I am not individually involved in cost saving projects."

"As an entry-level supervisor of one engineering corporation, I do not think that there are different responses given 
TABLE 6: The independent sample $t$-test coefficient summary of cost management by service/manufacturing industry.

\begin{tabular}{|c|c|c|c|c|c|c|c|}
\hline Indicators & Industry & $N$ & Mean & Std. deviation & Std. error mean & $t$ value & $p$ value \\
\hline \multirow{2}{*}{ Profit contribution } & Service & 90 & 4.378 & 1.195 & 0.126 & \multirow[t]{2}{*}{-2.848} & \multirow[t]{2}{*}{$\leqq .010$} \\
\hline & Manufacturing & 53 & 4.811 & 0.622 & 0.085 & & \\
\hline \multirow{2}{*}{ Revenue generation } & Service & 90 & 3.433 & 1.017 & 0.107 & \multirow[t]{2}{*}{-2.288} & \multirow[t]{2}{*}{$\leqq .050$} \\
\hline & Manufacturing & 53 & 3.774 & 0.750 & 0.103 & & \\
\hline \multirow{2}{*}{ Company reputation } & Service & 90 & 2.289 & 1.283 & 0.135 & \multirow[t]{2}{*}{3.801} & \multirow[t]{2}{*}{$\leqq .001$} \\
\hline & Manufacturing & 53 & 1.635 & 0.768 & 0.106 & & \\
\hline \multirow{2}{*}{ Quality assurance } & Service & 90 & 3.089 & 1.002 & 0.106 & \multirow[t]{2}{*}{1.295} & \multirow[t]{2}{*}{$\geqq .050$} \\
\hline & Manufacturing & 53 & 2.925 & 0.513 & 0.071 & & \\
\hline \multirow{2}{*}{ People management } & Service & 90 & 1.811 & 0.970 & 0.102 & \multirow[t]{2}{*}{-0.323} & \multirow[t]{2}{*}{$\geqq .050$} \\
\hline & Manufacturing & 53 & 1.868 & 1.093 & 0.150 & & \\
\hline
\end{tabular}

Source: authors.

by participants with personal involvement in the projects and participants without personal involvement. In any case, optimizing profit is what every organisation is seeking for. From the angle of $r$ cost management, they are those associated with revenue generation, profit contribution, and quality assurance."

Nonetheless, the remarks from an experienced human resource director point out that there might be some significant difference in the order of importance on people management for managing costs between the two sample groups (respondents personally involved and respondents not personally involved in cost saving projects).

"Based on my many years of observation and personal involvement in managing costs, personnel management has become more and more important as one of the main reasons for conducting cost reduction. Certainly, the significance of people management cannot be overemphasised. Contrastingly, it is less important if you do not have anything to deal with it."

The previously mentioned remarks are also in line with the questionnaire result in Table 7 , the mean score comparison result of "Rank for people management" was the group of "individual personally involved" $(M=0.91$, $D S=1.04)$ was slightly higher than the group of "Individual not personally involved" $(M=0.56, S D=0.83)$; however, it did not reach the significant level $(t=-1.89$, $p>0.05$ ) Cohen's $d$ or the standardized effect size represents the difference between the two means described in relation to common standard deviation to show the magnitude or strength of a stated relationship. If the difference is positive, it is in the way of improvement, and if it is negative, it then deteriorates [58].

In Table 7, Cohen's effect size displays that results from the sample group with personal involvement are not significantly different compared with the sample group without personal involvement on the rank for profit contribution $(p \geqq 0.05)$. On inspecting the means of these two sample groups, the average rank for profit contribution in respondents personally involved $(M=3.74)$ is not significantly higher than that in respondents not personally involved $(M=3.80)$. On the five-point test, the difference between these two means is 0.06 . The $d$-based effect size is about 0.08 , which indicates that the rank distribution for "participants personally involved" nearly covers the rank distribution for "participants not personally involved," as stated by Cohen [59].

In addition, the group "respondents personally involved" did not have a significant difference compared with the group "respondents not personally involved" on the ranks for revenue generation, quality assurance, organisational reputation, and people management, based on their $p$ values. The values of effect sizes $(d)$ excluding the rank for people management in Table 7 further indicate that the differences between these two sample groups are small or very trivial for revenue generation (0.20), organisational reputation $(0,05)$, and quality assurance (0.12). The negative $d$ on rank for people management $(d=-0.37)$ is still smaller than the "medium" effect size in this discipline but indicates a bigger effect for the group "individual not personally involved."

4.4. Model Development and Profit-Leverage Effect. Through the qualitative interviews and quantitative analyses approaches by industry type (service and manufacturing) and participant's personal involvement (whether participants personally involved in the cost management or not), the definitions for nonstrategic and strategic costs were tested and supported in the study. Strategic costs are redefined as any costs able to directly increase business profit, revenue, or product quality and value. Nonstrategic costs are then those costs needed to run the business but not able to directly contribute to the sales, profit, or product value and quality.

Strategic costs $\left(\mathbf{Y}_{\mathbf{s c}}\right)$ and nonstrategic costs $\left(\mathbf{Y}_{\mathbf{n s c}}\right)$ can be computed as follows to express how costs are categorised:

$$
\mathbf{Y}_{\mathrm{sc}}=\sum_{\mathbf{n}=\mathrm{cip}}^{\mathrm{qc}}\left(\mathbf{X}_{\mathrm{cip}}, \mathbf{X}_{\mathrm{cbb}}, \mathbf{X}_{\mathrm{edcb}}, \mathbf{X}_{\mathrm{ltc}}, \mathbf{X}_{\mathrm{dc}}, \mathbf{X}_{\mathrm{qc}}\right)
$$

where $\mathbf{Y}_{\text {sc }}$ is the strategic costs; $\mathbf{X}_{\text {cip }}$ is any cost spent to increase business profitability; $\mathbf{X}_{\mathbf{c b b}}$ is the cost spent to bring in more business; $\mathbf{X}_{\text {edcb }}$ is the expense directly related to the core business activity; $\mathbf{X}_{\mathbf{l t s}}$ is the labor costs directly related to sale; $\mathbf{X}_{\mathbf{d c}}$ is the direct costs; and $\mathbf{X}_{\mathbf{q c}}$ is the quality costs. Also, 
TABLE 7: Interpreting effect sizes (Cohen's $d$ ) and comparison of participants with/without individual involvement in the cost reduction.

\begin{tabular}{|c|c|c|c|c|c|c|c|}
\hline Variable & $M$ & $S D$ & $T$ & $D f$ & $p$ & Cohen's d & Effect size \\
\hline $\begin{array}{l}\text { Rank for profit contribution } \\
\text { Individual personally involved } \\
\text { Individual not personally involved } \\
\end{array}$ & $\begin{array}{l}3.74 \\
3.80 \\
\end{array}$ & $\begin{array}{l}0.81 \\
0.62 \\
\end{array}$ & 0.46 & 106 & 0.65 & 0.08 & - \\
\hline $\begin{array}{l}\text { Rank for revenue generation } \\
\text { Individual personally involved } \\
\text { Individual not personally involved } \\
\end{array}$ & $\begin{array}{l}2.57 \\
2.73 \\
\end{array}$ & $\begin{array}{l}0.89 \\
0.68 \\
\end{array}$ & 1.06 & 97.35 & 0.29 & 0.20 & - \\
\hline $\begin{array}{l}\text { Rank for company (organisation) reputation } \\
\text { Individual personally involved } \\
\text { Individual not personally involved } \\
\end{array}$ & $\begin{array}{l}0.77 \\
0.82 \\
\end{array}$ & $\begin{array}{l}1.07 \\
0.75 \\
\end{array}$ & 0.25 & 92.80 & 0.80 & 0.05 & - \\
\hline $\begin{array}{l}\text { Rank for quality assurance } \\
\text { Individual personally involved } \\
\text { Individual not personally involved } \\
\end{array}$ & $\begin{array}{l}2.00 \\
2.09 \\
\end{array}$ & $\begin{array}{l}0.68 \\
0.84 \\
\end{array}$ & 0.61 & 106 & 0.54 & 0.12 & - \\
\hline $\begin{array}{l}\text { Rank for people management } \\
\text { Individual personally involved } \\
\text { Individual not personally involved }\end{array}$ & $\begin{array}{l}0.91 \\
0.56\end{array}$ & $\begin{array}{l}1.04 \\
0.83\end{array}$ & -1.89 & 106.00 & 0.06 & -0.37 & Small \\
\hline
\end{tabular}

$n=61$ participants with personal involvement and 82 participants without personal involvement. *Effect sizes as "small, $d=0.2$ ", “medium, $d=0.5$," and "large, $d=0.8$ " defined by Cohen [59]; $n=90$ and 53 participants from service and manufacturing, respectively. Source: authors.

$$
\mathbf{Y}_{\text {nsc }}=\sum_{\mathbf{n}=\text { cnip }}^{\text {ic }}\left(\mathbf{X}_{\text {cnip }}, \mathbf{X}_{\text {cnbb }}, \mathbf{X}_{\text {endcb }}, \mathbf{X}_{\mathrm{ac}}, \mathbf{X}_{\text {lnts }}, \mathbf{X}_{\mathrm{ic}}\right) \text {, }
$$

where $\mathbf{Y}_{\mathbf{n s c}}$ is nonstrategic costs; $\mathbf{X}_{\text {cnip }}$ is the cost spent not increasing business profitability; $\mathbf{X}_{\mathbf{c n b b}}$ is the cost spent not directly bringing in more business; $\mathbf{X}_{\text {endcb }}$ is the expense not related directly to the core business activity; $\mathbf{X}_{\mathrm{ac}}$ is the administrative cost; $\mathbf{X}_{\mathbf{l n t s}}$ is the labor cost not directly related to sales; and $\mathbf{X}_{\mathbf{i c}}$ is the indirect cost.

As a further review of the study, Table 8 showed an analysis of 51 financial statements from 2009 to 2019 .

These selected companies in Table 8 were from the clients the researchers have associated with, and they were publicly listed companies or their related ledgers were in the files. The table is a work completed with the senior executives of participated enterprises together. As found in the table, $17.55 \%$ of net turnover (revenue) on average is nonstrategic costs. The findings support that strategic costs are much bigger than nonstrategic costs and the inferred percentage founded on the literature review. The study then established that the average percentage of nonstrategic costs is 10 to 30 percent of a firm's net revenues and the strategic costs usually represent 70 to 90 percent of its total costs. Properly managing strategic costs is essential for a company to stay in the market. The discipline of optimizing strategic costs should be employed to nonstrategic costs for being more competitive and outstanding, even those that might be the smaller portion. Yes, nonstrategic costs are the smaller portion but certainly not small and meaningless. Successfully managing nonstrategic costs can have a direct impact on the bottom line (i.e., profit, earnings before income tax). The profit-leverage effect translates the impact of saving nonstrategic costs to the revenue (sales) equivalent required to reach the same profit effect. A dollar saved in nonstrategic costs has a greater effect on profit than a dollar increase in revenue. After all, only a small share of each sales dollar has its contributions to the profit. The remainder is paid for the costs of doing business before bringing in the profit. On the flip side, every single dollar you earn through reducing nonstrategic costs gets directly to the profit. Reducing nonstrategic costs has a great impact on the financial results as showed in the following formula developed and supported by example:

$$
Y_{\mathrm{pnsc}}=\frac{X_{\mathrm{snsc}}}{Z_{\mathrm{pp}}},
$$

where the " $Y_{\text {pnsc }}$ " is profit-leverage effect of nonstrategic costs; " $X_{\text {snsc }}$ " is savings of nonstrategic costs; and " $Z_{\mathrm{pp}}$ " is profit percentage.

Le uss see the number effect through the analysis by example. Your profits are $\$ 5,000,000$, on sales of $\$ 100,000,000$, for a profit percentage of $5 \%(\$ 5,000,000 /$ $\$ 100,000,000)$. For every dollar of sales a firm makes, five cents only goes to the bottom line. As we saw previously, a dollar kept from nonstrategic costs contributes directly to profit and is, therefore, comparable to $\$ 20$ in new sales ( $\$ 1 /$ $\$ 0.05=\$ 20)$. In this case, $\$ 5,000,000$ savings are equal to $\$ 100,000,000$ sales. The $\$ 1$ saving effect is 20 times of $\$ 1$ sales. The profit-leverage effect of saving nonstrategic costs has a significant impact on a business's financial performance, which needs to be recognised. This clearly displays how every single dollar saved in nonstrategic costs gets straight to the profit, and it does so in the way that is more direct than it would be by improving revenue.

The finding here is not in favor of the viewpoint provided by Shufelt [18] that organisations focusing on nonstrategic costs and quick fixing produce a route map for failure. On the contrary, a necessity to pay extra attention to nonstrategic costs in the competitive scenario has been identified strategically [16]. Only about $20 \%$ of participants agreed with Shufelt's comment [18]. The majority of participants, $62.0 \%$, obviously did not agree with Shufelt's and conversely argued that a quick fix feature on managing nonstrategic costs will not result in a company's collapse. A finance manager of a public manufacturer also contended the following. 
TABLE 8: Percentage analysis of strategic cost and nonstrategic cost.

\begin{tabular}{|c|c|c|c|c|c|c|c|c|c|c|c|}
\hline \multirow[b]{2}{*}{ No. } & \multicolumn{2}{|c|}{ Strategic cost } & \multicolumn{2}{|c|}{ Nonstrategic cost } & \multirow{2}{*}{$\begin{array}{c}\text { Revenue } \\
£\end{array}$} & \multirow{2}{*}{ No. } & \multicolumn{2}{|c|}{ Strategic cost } & \multicolumn{2}{|c|}{ Nonstrategic cost } & \multirow{2}{*}{$\begin{array}{c}\text { Revenue } \\
£\end{array}$} \\
\hline & $£$ & $\%$ & $£$ & $\%$ & & & $£$ & $\%$ & $£$ & $\%$ & \\
\hline 1 & $23,485,343$ & 85.31 & $3,421,906$ & 12.43 & $27,529,414$ & 27 & $8,336,850$ & 59.6 & $2,268,994$ & 16.22 & $13,988,003$ \\
\hline 2 & $3,523,788$ & 56.19 & $1,387,190$ & 22.12 & $6,271,200$ & 28 & $17,610,672$ & 65.56 & $2,981,673$ & 11.10 & $26,861,916$ \\
\hline 3 & $10,532,754$ & 76.52 & $2,520,318$ & 18.31 & $13,764,707$ & 29 & $19,119,238$ & 88.97 & $3,341,622$ & 15.55 & $21,489,533$ \\
\hline 4 & $2,117,645$ & 73.26 & 567,423 & 19.63 & $2,890,588$ & 30 & $36,135,684$ & 76.43 & $11,072,847$ & 23.42 & $47,279,451$ \\
\hline 5 & $11,687,186$ & 69.03 & $3,648,542$ & 21.55 & $16,930,589$ & 31 & $528,898,143$ & 88.79 & $66,941,743$ & 11.24 & $595,673,097$ \\
\hline 6 & $38,929,655$ & 77.16 & $5,166,403$ & 10.24 & $50,453,156$ & 32 & $36,837,091$ & 67.54 & 7,564, & 13.87 & $54,541,147$ \\
\hline 7 & $11,027,440$ & 69.83 & $3,033,612$ & 19.21 & $15,791,838$ & 33 & $32,293,709$ & 74.87 & $7,315,364$ & 16.96 & $43,133,043$ \\
\hline 8 & $7,063,992$ & 75.47 & $2,566,512$ & 27.42 & $9,360,001$ & 34 & $4,399,102$ & 79.85 & 630,804 & 11.45 & $5,509,207$ \\
\hline 9 & $12,904,893$ & 71.09 & $3,654,178$ & 20.13 & $18,152,895$ & 35 & $65,676,062$ & 75.98 & $20,131,554$ & 23.29 & $86,438,618$ \\
\hline 10 & $24,437,111$ & 93.22 & $5,733,100$ & 21.87 & $26,214,451$ & 36 & $2,573,350$ & 86.5 & 648,841 & 21.81 & $2,974,972$ \\
\hline 11 & $7,973,309$ & 69.83 & $2,561,096$ & 22.43 & $11,418,171$ & 37 & $336,292,632$ & 73.76 & $43,509,227$ & 9.54 & $455,928,188$ \\
\hline 12 & $16,918,182$ & 74.69 & $2,734,000$ & 12.07 & $22,651,201$ & 38 & $36,552,500$ & 70.76 & $11,462,690$ & 22.19 & $51,657,009$ \\
\hline 13 & $5,303,693$ & 65.88 & $2,425,627$ & 30.13 & $8,050,537$ & 39 & $56,107,938$ & 78.76 & $9,239,715$ & 12.97 & $71,239,128$ \\
\hline 14 & $10,158,070$ & 64.32 & $3,329,168$ & 21.08 & $15,793,019$ & 40 & $41,858,003$ & 89.07 & $4,525,571$ & 9.63 & $46,994,502$ \\
\hline 15 & $37,822,378$ & 84.33 & 4,265 & & 44,8 & 41 & 70,87 & & 16,2 & 17.59 & 10,867 \\
\hline 16 & $10,282,114$ & 65.47 & $3,747,232$ & 23.86 & $15,705,078$ & 42 & $3,578,698$ & 66.98 & $1,499,227$ & 28.06 & $5,342,935$ \\
\hline 17 & $25,334,170$ & 74.34 & $4,208,730$ & 12.35 & $34,078,786$ & 43 & $343,444,622$ & 89.75 & $42,131,758$ & 11.01 & $382,668,103$ \\
\hline 18 & $57,620,997$ & 65.99 & $8,519,371$ & 9.76 & $87,321,741$ & 44 & $37,714,109$ & 63.63 & $10,064,208$ & 16.98 & $59,270,955$ \\
\hline 19 & $13,810,766$ & 67.54 & 2,480 & 12.13 & $20,447,272$ & 45 & $25,660,031$ & 62.11 & $9,002,288$ & 21.79 & $41,313,848$ \\
\hline 20 & $54,858,280$ & 65.41 & $13,779,568$ & 16.43 & $83,868,339$ & 46 & $284,447,915$ & 85.44 & $57,928,297$ & 17.4 & $332,921,249$ \\
\hline 21 & $24,677,865$ & 67.54 & $4,742,652$ & 12.98 & $36,538,148$ & 47 & $14,865,747$ & 75.12 & 4,199,297 & 21.22 & $19,789,333$ \\
\hline 22 & $9,320,974$ & 84.32 & $1,068,950$ & 9.67 & $11,054,287$ & 48 & $136,323,196$ & 76.54 & $46,857,537$ & 26.31 & $178,097,821$ \\
\hline 23 & $85,027,513$ & 64.53 & $28,500,621$ & 21.63 & $131,764,315$ & 49 & $7,090,195$ & 74.34 & $2,300,358$ & 24.12 & $9,537,138$ \\
\hline 24 & 8,715 & 69.28 & $1,315,778$ & 10.46 & $12,579,140$ & 50 & $10,335,397$ & 65.73 & $12,091,267$ & 28.51 & $15,724,257$ \\
\hline 25 & $5,618,005$ & 95.53 & $1,359,071$ & 23.11 & $5,880,880$ & 51 & $115,593,967$ & 95.41 & $12,091,267$ & 9.98 & $12,154,980$ \\
\hline \multirow[t]{2}{*}{26} & $212,124,163$ & 85.16 & $31,235,756$ & 12.54 & $249,088,966$ & Mean & 74.89 & & 17.55 & & \\
\hline & & & & & & SD & 9.57 & & 5.9 & & \\
\hline
\end{tabular}

Source: authors.

\begin{abstract}
"Well controlling those costs not related to business strategy, i.e., nonstrategic costs, should be treated as a positive thing for a company to enhance its competitive capabilities. Particularly, managing nonstrategic costs offers a fast way to increase the firm's bottom line in a short period. Besides, nonstrategic costs are not necessary for running a company. Minimising them has no harm to a company's core competence. I certainly do not think that reducing nonstrategic costs will bring a company to the road of failure. Oppositely, it could be a smart move to remain competitive in difficult times."
\end{abstract}

It was found also that if the same amount of attention was paid to strategic costs, the saving rate would be much lower than that of nonstrategic costs [16]. The president of a listed Taiwanese company in the lighting industry said the following.

"We found very limited space for further improving strategic costs when we keep wringing out them. However, higher saving rate has been delivered after spending much less time on reducing those nonstrategic expenses such as packaging, telecommunication, insurance, etc., although they are relatively small in comparison with strategic costs."

A financial officer from a publicly owned distributor in auto parts business agreed that higher savings over nonstrategic overhead expenses can be expected:
"Under the facilitation of an external consultant, we increased our attention on nonstrategic overhead expenses and successfully achieved a saving of up to $25 \%$ on administration expenses. The result was never delivered for strategic costs".

A vice president from an original equipment manufacturer (OEM) located in a science park indicated the following.

"Our profit margin has been very slim. The cost structure in the industry is transparent and no big difference among market competitors. To survive in the market, every nonstrategic dollar needs to be reviewed. We should not keep ignoring them. They are our survival kit."

A group head of retail chain commented as follows.

"Continuously reducing costs is why our group can always lead the market....But, I cannot agree more than we did not pay enough attention on nonstrategic costs. The newly launched programs aiming at reducing nonstrategic costs have showed that higher rates and savings can be accomplished in comparison with strategic costs."

A senior manager's commentaries support that a higher saving from nonstrategic cost can be expected: 
"My company accustomed to watch over big cost items, i.e., strategic costs ......We really struggled to have more savings after trying so many efforts..... Nonstrategic costs which are not critical to the core business however can be saved quickly without making too much effort. The quick money is certainly good money to my company. Nonstrategic costs are the low-hanging fruits, easy money to make. Besides, firstly reducing nonstrategic costs can avoid losing our core capabilities or advantages due to unthoughtfully cutting strategic costs."

A senior expatriate in charge of daily operation complained as follows.

"Inefficient reporting lines, unclear definition of costs or expenses unnecessary to be spent...... We undoubtedly neglect nonstrategic costs. The company certainly needs to review nonstrategic costs to improve its profit"

The previously mentioned interviews evidently support the survey results. The statements also clearly deliver messages that higher savings on nonstrategic costs can be achieved, in comparison with strategic costs. Nonstrategic costs are often neglected in the firms and can be reduced more easily without impairing primary activities in the business.

The research was to investigate a clear connection between organisational profit and nonstrategic costs, which is not a conventional emphasis by organisations; nonstrategic costs did not have the attention as strategic costs and sales had at the first instance [16]. Having a higher rate of cost saving from nonstrategic costs than from strategic costs is foreseeable if more attention can be paid to nonstrategic costs [16]. According to the report from CFO research services [60], a $20 \%$ average saving on nonstrategic costs could be realised; that is, profit enhanced by $2 \%$ at least. Nonstrategic costs are the potential source to strategically enhance competitive advantage after putting so much effort into strategic costs. The meaningfulness of nonstrategic costs should not be ignored. The release of hidden profit through reducing nonstrategic costs made by administrative personnel and people involved should be recognised.

The findings conclude that there is a strategic position for nonstrategic costs to enhance organisational sustainability and leave market players far behind if nonstrategic costs can be minimised by taking a strategic view.

4.5. The Managerial Implication of the Study. Conceptual thinking of strategic or nonstrategic has been considered by a few business practitioners and academic researchers but applied in different areas without rigorous definitions through academic route. Dealing with the long business impact of COVID-19 and tough economic times by wisely managing costs in a strategic way is now becoming an essential challenge for the business industry. The novelty of strategic mathematical computing model and triangulated approach in the proposed methodology provides an innovated way of encouraging a more proactive and positive cost control within the organisation to manage nonstrategic costs strategically, which is never the emphasis in the prior studies. In comparison with the existing literature, the study draws important insights into the management of nonstrategic costs and the strategic mathematical computing model to indicate the importance of managing the nonstrategic costs that slip shortly in business costs, compared to the strategic costs, when people noticed about it. The nonstrategic cost area not traditionally focused by firms is not a main academic research stream of cost management but is essential for firms to stand out among market players rather than surviving only in a difficult economic environment. How organisations prepare for the next normal after COVID-19 through minimising nonstrategic costs certainly increases business sustainability and competitive advantage.

\section{Conclusions}

It is the time to view costs from a strategic standpoint and make nonstrategic costs strategic as the key managerial implications of this study. The present study highlights the significance of nonstrategic costs and contributes several important findings in cost management. First, (1) and (2) that categorise costs into two types, strategic and nonstrategic costs, are found to be an effective and straightway to review costs from a strategic perspective. Second, nonstrategic cost is the neglectfully hidden source to enhance profit (the bottom line) for business sustainability and competitive advantage. Third, the profit-leverage effect formula of nonstrategic costs (3) is always advantageous for motivating the initiation of managing nonstrategic costs. Fourth, the average profit enhanced by $2 \%$ is directly contributed to the business bottom line if nonstrategic costs can be properly managed. Fifth, the alternative cost reduction based on managing nonstrategic costs resolves the dilemma of laying employees off, forges a stronger bond between employees and firms, and raises morale in the workplace as corporate social responsibility (CSR) refers to strategies that companies put into action as part of corporate governance to ensure that the company's operations are ethical and beneficial for the community. Obviously, this is appropriate to take actions against nonstrategic costs before strategic costs without weakening a firm's core competency.

5.1. Survey Results. In addition to the literature review, multiple approaches including questionnaires and interviews were used to investigate the strategic position and significance of nonstrategic costs. Furthermore, this study aimed to enhance organisational profit and competitive advantage by emphasizing the importance of managing nonstrategic costs. A direct connection between the degree of cost tracing and the percentage of costs exists across industries $[16,40]$, which indicates that the main cost portion (strategic costs) is more actively managed due to the high-relative degree of tracing and closer monitory. Consequently, there is less opportunity to save more from strategic costs compared with nonstrategic costs. Pareto 
analysis has been widely applied in various areas to reshuffle data for decision purposes and strategic emphasis on a few crucial tasks [16, 61-65]. Of the tasks an organisation deals with, only $20 \%$ is really essential to be competitive and outstanding from other market players. In this research, the $20 \%$ means that there is a necessity for giving more attention and expanding the control of strategic costs to nonstrategic costs. The $20 \%$ percent, nonstrategic costs, produce $80 \%$ of results as an effective reduction of nonstrategic costs can generate a higher saving rate than would be delivered from strategic costs.

Cost management should not be restricted to costs only but ought to also think through profit, revenue, product, and service value and the strategic position in the meantime. In addition, to validate and support the definitions of strategic and nonstrategic costs from previous studies and field practitioners, the research highlights the strategic significance of reducing nonstrategic costs to convey a broad application of strategic cost management needs. The research concludes that managing nonstrategic costs is an attitude, a belief, and a strategy to enhance business sustainability and competitive advantage. Most importantly, it helps a company to cut nonstrategic costs without jeopardizing the business. Moreover, adopting the idea of cost leadership to maximize profit, managing nonstrategic costs effectively is a sensible initiative in difficult times. The rationale behind cutting nonstrategic costs is that firms should minimise nonstrategic costs to be more competitive. In contrast, it is risky to reduce strategic costs without thorough consideration.

\subsection{Recognition of Administrative Personnel on Profit-Le-} verage Effect. The profit-leverage effect dictates that decreasing costs is more efficient than increasing revenue. The administration department and related personnel in firms are often the people standing to leverage the savings on nonstrategic costs into profit. Positioned at the initial stage of effectively managing nonstrategic costs, the administrative personnel are in a strong position to initiate the savings of nonstrategic costs and echo the importance of heavy and active involvement from individuals in the action. For firms, an increase in sales without the increase in strategic costs would be a huge challenge. Alternatively, reducing nonstrategic costs by $10 \%$ to $30 \%$ is very achievable for organisations that have not treated the management of nonstrategic costs seriously.

Even if the administration department functioned as a cost center, CEOs can instruct the organisation unambiguously to work in a cross-functional manner for jointly reducing nonstrategic costs, but the savings generated can be shared by related parties or remain within each functional group. With this in mind, administrative personnel and related parties should be rewarded for their cost reduction efforts to sales equivalent required on bringing up the company's profits. They are not only cost spenders, but also important profit generators. Every dollar saved through reducing nonstrategic costs gets straight to the business profit as aforesaid. Conversely, only a few sales really go to the profit after deducting a large number of costs associated with doing business. Do not simply value the financial impact of reducing nonstrategic costs from the saving amount instead of the profit-leverage effect on sales equivalent required. It will be sensible to reward administrative personnel and related parties who provide value and impact revenue in indirect ways but profit indirect ways.

5.3. Contribution to Practice and Knowledge. The study demonstrated that separating costs into nonstrategic and strategic is viable to employ across sectors, industries, and business scales in comparison with others. Besides a review of 51 financial statements from various firms, the study provided formulas for catering costs into nonstrategic and strategic costs to support the assumption of nonstrategic costs accounting for about $10 \%$ to $30 \%$ of company's revenue and confirmed the finding that strategic costs are greater than nonstrategic costs. The study quested for more positive control over nonstrategic costs by measuring their profit-leverage effects and inspired the participants in the research to extend the concept of strategic cost management to nonstrategic costs. Some examples are as follows:

(i) Three participants successfully included the profit contribution resulting from reducing nonstrategic costs in the balanced scorecard for employee's performance review to correct the carelessness of nonstrategic costs in their own companies.

(ii) A local commercial bank has introduced a proportioned cost ratio of strategic against nonstrategic to outspend their competition on strategic costs by minimising nonstrategic costs.

(iii) A managing attorney of law offices has asked her direct reporting staff to hand over their timesheets with time allocation by type, strategic time, and nonstrategic time, based on their direct connection with business profit. Therefore, she is able to assess if they are really productive or not.

(iv) Participating in the research, a chair lady learnt to sort all cost items neglected into her monthly business checking list. "Sales first always" is no longer her only main priority. During the COVID19 pandemic, the chair lady has closely minimised all nonstrategic costs unnecessary.

It is argued that the workable solution by making nonstrategic costs strategic as an alternative cost leadership paradigm can support a sensible perception of cost management and make a specific contribution to the practice. There may be other related studies suitable for adopting a similar methodology and realise the findings and savings via the scholastic path.

The employment of the scholastic route is a keystone to further provide solutions with case studies for academic researchers, business consultants, and management 
TABLe 9: The summary of key research questions answered in the study.

Question
Is there significant difference on doing cost management across
industry for reasons including profit contribution, revenue
generation, company reputation, quality assurance, people
management, or other specified?
Is there significant difference on the importance of cost
management for the reasons (including profit contribution, revenue
generation, company reputation, quality assurance, people
management) if the respondent's involvement in the cost
management is taken into consideration?

Is reducing nonstrategic costs a path to failure? Can managing nonstrategic costs be a strategic advantage to business profit and sustainability?
Answer

No, no significant deviation exists across industries. However, manufacturers give significantly more importance to profit contribution and service companies give significantly greater importance to quality assurance.

No, the sample group of "individuals personally involved" did not differ significantly from the sample group of "individuals not personally involved" on the ranks for reasons of conducting cost management although the views on people management (the most insignificant category) do get close to significance at the $5 \%$ level.

Yes, reducing nonstrategic cost item is a wise move to enhance a firm's strategic position and is not a roadmap created for business collapse. Managing nonstrategic costs by taking a strategic view can enhance a firm's competitive advantage and sustainability. Managing nonstrategic costs is an alternative cost leadership paradigm to enhance business profit in difficult times

Yes, a review of 51 companies confirmed the assumption. Less Is the assumption that nonstrategic costs accounting for 10 to 30 attention is often given due to the nature of relatively small portion
percent of a company's revenue in line with reality? Is it meaningful compared to strategic costs, resulting in higher saving rate and easier to cut nonstrategic costs, the minor portion? competitors than from strategic costs.

Source: authors.

executives. However, future research is needed to develop a framework and bring all stakeholders together for jointly delivering a potential profit contribution of $10 \%$ to $30 \%$ extra saving over nonstrategic costs.

The researchable questions in the study are answered and summarised in Table 9.

Not only the previously mentioned questions were clearly answered but also the strategic importance of nonstrategic costs was confirmed. Strategic costs have to be well managed, but more care should be paid to nonstrategic costs. This study draws important insights into the management of nonstrategic costs in tough economic times such as the COVID-19 pandemic recession to strategically release hidden profit and then enhance a company's competitive advantage and sustainability. Thus, advanced study is desired to develop a practical framework of managing nonstrategic costs with a supportive case for truly realising the saving effects of nonstrategic costs. However, "there is no such thing as a free lunch" describes the cost of decisionmaking and consumption. The value of benefits resulting from minimising nonstrategic costs involves certain costs or sources spent. To justify the initiative and lift the limitation of the model, the future extension of this study is to explore if the efforts on managing nonstrategic costs are cost-effective when conducting a saving project. Cost/benefit analysis and return on investment are measures often used by financial managers to gauge the efficiency and effectiveness of their budget policies.

The research can be also further extended in several directions to achieve broader insights. For instance, in a real business scenario, some negative cost effectiveness may occur for performing saving projects in-house. Outsourcing it to maximize profit/benefit can then be the better choice.

Lastly, it is acknowledged by the study's authors that the empirical research was conducted with firms in the context of the present condition of two sides of Taiwan Strait and global economy, rather than with organisations located in other countries under different economic context. Additional samples from other countries and continents could be needed to reach generalisability for widely accepting the findings in the future study.

\section{Data Availability}

Data used to support the study are available with the authors upon request.

\section{Conflicts of Interest}

The authors declare that they have no conflicts of interest.

\section{References}

[1] A. A. Choudhari, "Techniques to reduce the cost of raw material and to gain the profits," International Research Journal of Engineering and Technology, vol. 5, no. 8, pp. 132-135, 2018.

[2] E. F. Harry, The Cost Reduction and Profit Improvement Handbook, CBI Publishing Company, Boston, MA, USA, 1983.

[3] N. V. K. Jasti, S. Kota, and S. R. Kale, "Development of a framework for lean enterprise," Measuring Business Excellence, vol. 24, pp. 1-29, 2020. 
[4] E. Blocher, K. Chen, and T. Lin, Cost Management: A Strategic Emphasis, McGraw-Hill, New York, NY, USA, 1999.

[5] R. Cooper and R. Slagmulder, "Strategic cost management: what is strategic cost management?" Management Accounting, vol. 79, no. 7, pp. 14-16, 1998.

[6] R. Cooper and R. Slagmulder, "Strategic cost management: the scope of strategic cost management," Management Accounting, vol. 79, no. 8, pp. 16-18, 1998.

[7] R. Cooper and R. Slagmulder, "Strategic cost management: extra-organisational cost analysis," Management Accounting, vol. 79, no. 1, pp. 14-16, 1998.

[8] X. Ding, K. Liu, and S. Shi, "Risk assessment of strategic cost management based on grey model for prefabricated buildings," International Journal of Performability Engineering, vol. 16, no. 9, pp. 1478-1487, 2020.

[9] R. Hansen and M. Mowen, Cost Management: Accounting and Control, South-Western College Publishing, Mason, $\mathrm{OH}$, USA, 3rd edition, 2000.

[10] J.-F. Henri, O. Boiral, and M.-J. Roy, "Strategic cost management and performance: the case of environmental costs," The British Accounting Review, vol. 48, no. 2, pp. 269-282, 2016.

[11] R. Hilton, M. Maher, F. Selto, and B. Sainty, Cost Management: Strategies for Business Decisions, McGraw-Hill, Ryerson, NY, USA, 2001.

[12] J. McDowell, "Achieving strategic cost advantages by focusing on back-office efficiency," Healthc Financ Manage, vol. 64, no. 6, pp. 98-104, 2010.

[13] C. McNair, "Defining and shaping the future of cost management," Journal of Cost Management, vol. 8, pp. 28-32, 2000.

[14] B. Fifer, Double Your Profits, Harper Business, New York, NY, USA, 1994.

[15] S. Machin, "Strategic VS. nonstrategic cost," 2007, http:// www.thegaap.net/articles/strategic_VS_Nonstrategic_Costs. html.

[16] Y. C. Yeh, "Releasing hidden profit through taking a strategic view of nonstrategic costs," https://www.napier.ac.uk/ /media/worktribe/output-177096/yeh09013248dbadocx. pdfDoctoral dissertation, Edinburgh Napier University, Edinburgh, UK, 2014, https://www.napier.ac.uk/ /media/ worktribe/output-177096/yeh09013248dbadocx.pdfDoctoral dissertation.

[17] M. M. Hakim, "Information system strategic planning in IS/ IT service provider," Jurnal Ilmiah Penelitian Dan Pembelajaran Informatika, vol. 2, no. 2, pp. 118-127, 2017.

[18] J. Shufelt, Training Prepares, Experience Sells, Industrial Distribution, New York, NY, USA, 2003.

[19] D. Finkel, "The difference between strategic and nonstrategic spending and why it matters? do you know the difference between the two?" Newsletters, vol. 25, 2020, https://www.inc. com/david-finkel/the-difference-between-strategicnonstrategic-spending-why-it-matters.html.

[20] T. Grant, 2017 Government Contractor Survey, Professional Service Council, New York, NY, USA, 2018.

[21] M. E. Porter, Competitive Strategy: Techniques for Analyzing Industries and Competitors, Free Press, New York, NY, USA, 1980.

[22] A. Atkinson, R. Banker, R. Kaplan, and S. M. Young, Management Accounting, Prentice-Hall, New York, NY, USA, 2004.

[23] S. S. Sana, "Price competition between green and non green products under corporate social responsible firm," Journal of
Retailing and Consumer Services, vol. 55, Article ID 102118, 2020.

[24] S. S. Sana, "A structural mathematical model on two echelon supply chain system," Annals of Operations Research, vol. 28, 2021.

[25] T. Grundy, "Cost is a strategic issue," Long Range Planning, vol. 29, no. 1, pp. 58-68, 1996.

[26] R. Cooper, "Look out, management accountants," Management Accounting, vol. 77, no. 11, pp. 20-26, 1996.

[27] T. Bartram, J. Cavanagh, and R. Hoye, "The growing importance of human resource management in the NGO, volunteer and not-for-profit sectors," The International Journal of Human Resource Management, vol. 28, no. 14, pp. 1901-1911, 2017.

[28] A. Dubois, "Strategic cost management across boundaries of firms," Industrial Marketing Management, vol. 32, no. 5, pp. 365-374, 2003.

[29] H. Ying, "Summary of the research on strategic cost management," Journal of Beijing Technology and Business University, vol. 1, pp. 23-37, 2004.

[30] J. Shank and V. Govindarajan, Strategic Cost Management: The New Tool for Competitive Advantage, Free Press, New York, NY, USA, 1993.

[31] B. Welfle and P. Keltyka, "Global competition: the new challenge for management accountants," Ohio CPA Journal, vol. 59 , no. 1 , p. $30,2000$.

[32] P. Horváth and A. Brokemper, "Strategieorientiertes kostenmanagement," Zeitschrift für Betriebswirtschaft, vol. 68, no. 6, pp. 581-604, 1998.

[33] H. Wei, Y. Wang, J. Rong, and J. Weng, "ICCTP 2010: integrated transportation systems green, intelligent, reliable," in Proceedings of the Tenth International Conference of Chinese Transportation Professionals, Beijing, China, The American Society of Civil Engineers (ASCE), Reston, VA, USA, August 2010.

[34] J. Maeda, The Law of Simplicity, The MIT Press, Boston, MA, USA, 2006.

[35] R. Evans, "“Reaping the full benefits of end-user computing," Computer World. Framingham, vol. 23, no. 34, pp. 67-71, 1989.

[36] R. A. Noe and A. D. Kodwani, Employee Training and Development, McGraw-Hill Education, New York, NY, USA, 7th edition, 2018.

[37] T. J. Green, Z. G. Ives, and V. Tannen, "Reconcilable differences," Theory of Computing Systems, vol. 49, no. 2, pp. 460-488, 2011.

[38] J. Lee and M. Covell, "A strategic approach to overhead management," Strategy \& Leadership, vol. 36, no. 2, pp. 40-46, 2008.

[39] P. Ludy, Profit Building: Cutting Costs without Cutting People, Berrett-Koehler Publishers, San Francisco, CA, USA, 2000.

[40] C. J. Chang and N.-C. R. Hwang, "The effects of country and industry on implementing value chain cost analysis," The International Journal of Accounting, vol. 37, no. 1, pp. 123140, 2002.

[41] R. Groff, Critical Realism, Post-Positivism and the Possibility of Knowledge, Routledge, London, UK, 2004.

[42] D. C. Phillips and N. C. Burbules, Post-positivism and Education Research, Rowman and Littlefield Publishers, Lanham, MD, USA, 2000.

[43] P. Barron, Post-positivism, For DBA Unit 3 of Edinburgh Napier University, Edinburgh, UK, 2010.

[44] P. Rothbauer, "Triangulation," in The SAGE Encyclopedia of Qualitative Research Methods, A. Lisa, Ed., Sage Publications, New York, NY, USA, pp. 892-894, 2008. 
[45] I. Etikan, R. Alkassim, and S. Abubakar, "Comparision of snowball sampling and sequential sampling technique," Biometrics \& Biostatistics International Journal, vol. 3, no. 1, pp. 55-56, 2016.

[46] P. Atkinson and M. Hammersley, Ethnography: Principles in Practice, Routledge, London, UK, 1989.

[47] M. Birbili, "Using connections to gain access: some points of caution," in Explorations in Methodology (Studies in Educational Ethnography), A. Massey, Ed., vol. 2, pp. 17-28, Emerald Group, Bingley, UK, 1999.

[48] M. Easterby-Smith, R. Thorpe, and A. Lowe, Management Research: An Introduction, Sage, London, UK, 2nd edition, 2002.

[49] MOEA, Taiwan, The Number of Enterprises, Employed Persons and Total Sales in SMEs Have Grown Stably in 2019," Small and Medium Enterprise Administration, Ministry of Economic Affairs R.O.C., Taiwan, China, 2019, https://www. moeasmea.gov.tw/article-en-2442-5864.

[50] Ministry of Economic Affairs, Taiwan Small and Medium Enterprises See Steady Growth, Taiwan News, Taiwan, China, 2019, https://www.taiwannews.com.tw/en/news/3811346.

[51] SME Bureau of MIIT, China, 2019 Business Operation Report of Small and Medium-Sized Enterprises in China, SME Bureau, Ministry of Industry and Information Technology of P.R.C., Beijing, China, 2019, http://lwzb.stats.gov.cn/pub/lwzb/bztt/ 202011/W020201129800248235976.pdf.

[52] J. McCormack, B. Vandermeer, and G. M. Allan, "How confidence intervals become confusion intervals," $B M C$ Medical Research Methodology, vol. 13, no. 1, pp. 1-6, 2013.

[53] S. H. Tan and S. B. Tan, "The correct interpretation of confidence intervals," Proceedings of Singapore Healthcare, vol. 19, no. 3, pp. 276-278, 2010.

[54] N. M. Modak, N. Modak, S. Panda, and S. S. Sana, “Analyzing structure of two-echelon closed-loop supply chain for pricing, quality and recycling management," Journal of Cleaner Production, vol. 171, pp. 512-528, 2018.

[55] A. A. Taleizadeh, M. Noori-Daryan, and S. S. Sana, "Manufacturing and selling tactics for a green supply chain under a green cost sharing and a refund agreement," Journal of Modelling in Management, vol. 15, no. 4, pp. 1419-1450, 2020.

[56] K. Al-Naser and R. Mohamed, "The integration between strategic cost management techniques to improve the performance of Iraqi manufacturing companies," Asian Journal of Finance \& Accounting, vol. 9, no. 1, pp. 210-223, 2017.

[57] D. M. Mihaiu, A. Opreana, and M. P. Cristescu, "Efficiency, effectiveness and performance of the public sector," Romanian Journal of Economic Forecasting, vol. 4, no. 1, pp. 132147, 2010.

[58] L. A. Becker, "Effect size (ES)," 2000, http://www.bwgriffin. com/gsu/courses/edur9131/content/EffectSizeBecker.pdf.

[59] J. Cohen, Statistical Power Analysis for the Behavioral Sciences, Lawrence Erlbaum Associates, Mahwah, NJ, USA, 2nd edition, 1988.

[60] CFO Research Services, Bring the Discipline of Direct Cost Management to Grand a Costs, CFO Publishing Corp, New York, NY, USA, 2009.

[61] E. Berniker and D. E. McNabb, "Applying matrixed pareto analysis with activity based costing for operation," Journal of Business and Management, vol. 11, no. 1, pp. 73-88, 2005.

[62] H. Azari-Rad, "Inventory dynamics, time lags, and efficiency measures," International Journal of Production Economics, vol. 87, no. 1, pp. 17-24, 2004.
[63] R. Rai and V. Allada, "Modular product family design: agentbased pareto-optimization and quality loss function-based post-optimal analysis," International Journal of Production Research, vol. 41, no. 17, pp. 4075-4098, 2003.

[64] R. D. H. Wharburton, "An exact analytical solution to the production inventory control problem," International Journal of Production Economics, vol. 92, no. 11, pp. 81-96, 2004.

[65] S.-B. Tsai, J. Yu, L. Ma et al., "A study on solving the production process problems of the photovoltaic cell industry," Renewable and Sustainable Energy Reviews, vol. 82, pp. 3546-3553, 2018. 